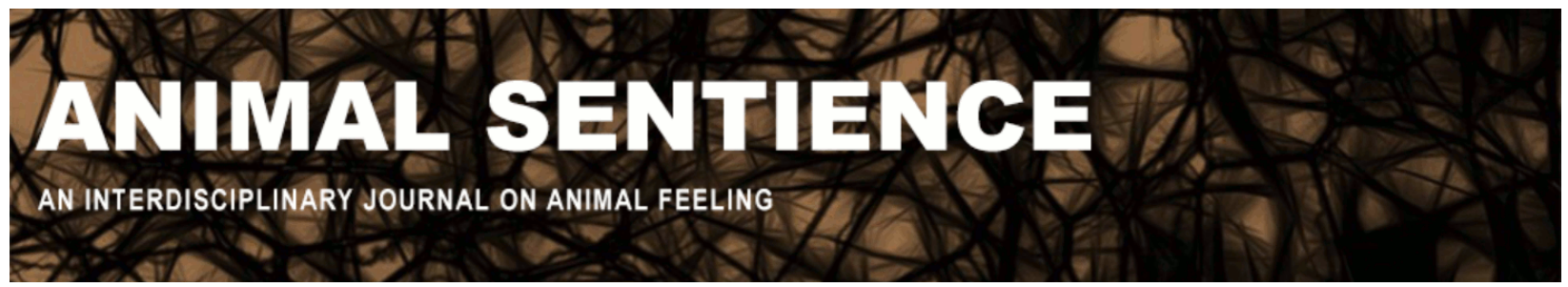

Gradidge, Sarah and Zawisza, Magdalena (2019) Why factual appeals about the abilities of sheep may fail. Animal Sentience 25(42)

DOI: $10.51291 / 2377-7478.1500$

Date of submission: 2019-07-01

Date of acceptance: 2019-08-06

(c)

This article has appeared in the journal Animal

Sentience, a peer-reviewed journal on animal

cognition and feeling. It has been made open access,

free for all, by WellBeing International and deposited

in the WBI Studies Repository. For more information,

please contact

wbisr-info@wellbeingintl.org.

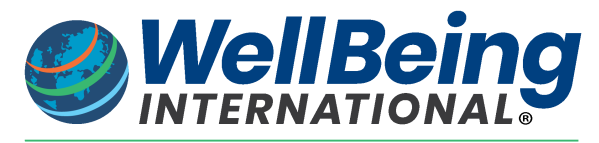

SOLUTIONS FOR PEOPLE, ANIMALS AND ENVIRONMENT 


\title{
Why factual appeals about the abilities of sheep may fail
}

Commentary on Marino \& Merskin on Sheep Complexity

\author{
Sarah Gradidge \& Magdalena Zawisza \\ Department of Psychology \\ Anglia Ruskin University, UK
}

\begin{abstract}
Marino \& Merskin (2019) express hope that providing people with positive information about the abilities of sheep (factual appeals) will improve perceptions of them and thus improve their welfare. However, these factual appeals can, and do, fail to change perceptions of animals. This commentary considers why and when factual appeals fail, and with whom they may be effective.
\end{abstract}

Sarah Gradidge, doctoral candidate in Psychology at ARU, Cambridge, and editor of Psychobabble, studies speciesism, its causes and interventions. Website

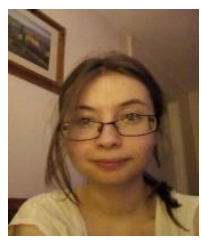

Magdalena Zawisza, Reader at ARU, Cambridge, does research on social, gender and consumer psychology. Website

Marino \& Merskin (M\&M, 2019) provide an informative review about the abilities of sheep, about which the majority of people are probably unaware. M\&M suggest that many people incorrectly stereotype sheep as unintelligent. They accordingly recommend that highlighting (counterstereotypical) information about sheep abilities (factual appeals) will improve our perception of sheep and, by extension, their welfare. However, as we discuss here, the psychological literature suggests that such factual appeals can fail because of motivated cognition and self-relevance. Motivated cognition is a biased form of reasoning, whereby we interpret information in ways favourable to us (Balcetis, 2008); self-relevance refers to the extent to which an animal is used by any one individual (e.g., as food, clothing, or entertainment; Piazza \& Loughnan, 2016). Hence sheep are self-relevant for people who consume sheep (lamb) or other sheep products (e.g., wool).

1. Previous commentaries. Previous commentaries have referred to the widespread use of sheep as property or commodities (e.g., Baker, 2019; Correia Caeiro, 2019; Davis, 2019; Hermanson, 2019; Palmer \& Sandøe, 2019; Rollin, 2019; Sevillano, 2019; Woodford \& Carter, 2019). Some suggested that our negative perceptions of sheep result from our treating them as property (Correia Caeiro, 2019; Davis, 2019). We will try to expand upon this idea of "sheep as property" by considering exactly why it motivates people to perceive them negatively (because of motivated 
cognition and self-relevance) and why people may therefore dismiss factual appeals regarding sheep (cf. Furlong et al., 2018). We also go beyond Davis's (2019) work by offering some hope and considering how factual appeals may be effective with certain audiences.

2. Why may factual appeals fail? People are less willing to help and feel less empathy for selfrelevant animals (e.g., sheep, pigs) compared to non-self-relevant animals (e.g., dogs) (Gradidge, 2018). To address this problem, it is important to develop interventions that encourage more positive perceptions of self-relevant animals. Unfortunately, factual appeals may not work, as people often use motivated cognition when evaluating self-relevant animals, including sheep, to maintain a favourable self-image. For example, information about the high intelligence of pigs is typically ignored (Piazza \& Loughnan, 2016). Participants give pigs the same moral status regardless of whether pigs are described as having high or low intelligence. This does not apply to dogs or fictional animals, neither of whom are self-relevant (e.g., as food) animals. Instead, perceived moral status is higher when dogs or fictional animals are described as high in intelligence and lower when described as low in intelligence. As both pigs and sheep are selfrelevant profit animals bred for consumption, these findings probably apply to sheep as well, suggesting that people will also ignore positive information about the intelligence of sheep.

Individuals can also ignore the emotional and physiological abilities of animals, including their ability to suffer or feel physiological pain (e.g., Bratanova, Loughnan, \& Bastian, 2011). Thus, not only can animals be construed as unintelligent; they can also be evaluated as incapable of suffering and feeling pain, making it morally permissible to consume them. Because of motivated cognition and self-relevance, factual appeals may fail; the information they contain is easily ignored, enabling individuals to maintain a favourable self-image. Hence factual appeals about sheep will not necessarily improve perceptions in consumers for whom sheep are self-relevant.

3. With whom may factual appeals work? People use various strategies to distance themselves from animals they consume (Gradidge, Zawisza, \& Harvey, under review). Some use direct strategies (Rothgerber, 2012), including denial of animal suffering and denial of animal mind. These strategies morally justify consuming animals, as their perceived inability to think or suffer renders consuming them harmless. Such individuals can maintain a positive self-concept despite consuming animals. It is therefore unlikely that people using direct strategies will respond positively to factual appeals (Rothgerber, 2012). In fact, they may respond to factual appeals negatively (Dowsett, Semmler, Bray, Ankeny, \& Chur-Hansen, 2018; Feinberg, Kovacheff, Teper, \& Inbar, 2019; Rothgerber, 2014). For example, people who deny animals' emotions or their ability to suffer can, following exposure to factual appeals, subsequently view meat consumption as more acceptable morally than they did prior to exposure (Feinberg et al., 2019).

Some meat consumers utilise indirect strategies, which often include dissociation from consumed animals (e.g., not thinking about these animals or avoiding information about them; Rothgerber, 2012). Factual appeals can disrupt dissociation in individuals who use indirect strategies (Dowsett et al., 2018) and can thus encourage them to view animals positively and reduce their animal consumption (Kunst \& Haugestad, 2017; Kunst \& Hohle, 2016). Demographically, females (Rothgerber, 2012) or those who value masculinity less (Kildal \& Syse, 2017), and individuals from countries less exposed to animal slaughter (e.g., UK, US, France; Kunst \& Haugestad, 2017; Tian, Hilton, \& Becker, 2016), are more likely to use indirect strategies. Males 
or those who value masculinity more, and individuals from countries more exposed to animal slaughter (e.g., China, Ecuador) are more likely to use direct strategies. Factual appeals may therefore be more effective when targeting audiences that use indirect strategies, although further research should test this hypothesis directly.

4. Conclusion. Factual appeals based on animals' abilities should only be used when likely to be effective. Further research should investigate how factual appeals can be made more effective, particularly amongst individuals using direct strategies. Perhaps individuals can be encouraged to use indirect strategies, and then factual appeals would be more effective. Alternatively, research may show that we should abandon factual appeals altogether with this group and seek alternative interventions.

\section{References}

Baker, L. (2019). Is knowing enough to change human attitudes and actions? Animal Sentience 25(4).

Balcetis, E. (2008). Where the motivation resides and self-deception hides: How motivated cognition accomplishes self-deception. Social and Personality Psychology Compass, 2(1), 361-381. doi: 10.1111/j.1751-9004.2007.00042.x

Bratanova, B., Loughnan, S., \& Bastian, B. (2011). The effect of categorization as food on the perceived moral standing of animals. Appetite, 57(1), 193-196. doi:

10.1016/j.appet.2011.04.020

Correia Caeiro, C. (2019). Cognitive dissonance about sheep cognition and consumption. Animal Sentience 25(39).

Davis, H. (2019). Our disparaging view of sheep is indeed based on cognitive inadequacy: Unfortunately, it's ours. Animal Sentience 25(20).

Dowsett, E., Semmler, C., Bray, H., Ankeny, R. A., \& Chur-Hansen, A. (2018). Neutralising the meat paradox: Cognitive dissonance, gender, and eating animals. Appetite, 123, 280-288. doi: 10.1016/j.appet.2018.01.005

Feinberg, M., Kovacheff, C., Teper, R., \& Inbar, Y. (2019). Understanding the process of moralization: How eating meat becomes a moral issue. Journal of Personality and Social Psychology. Advance online publication. doi: 10.1037/pspa0000149

Furlong, E., Silver, Z., \& Furlong, J. (2018). Anthropocentrism as cognitive dissonance in animal research? Animal Sentience 12(11).

Gradidge, S. (2018). "Breaking news: Animal stolen!": How personalisation and species affect perceptions of animal victim (MSc dissertation, Anglia Ruskin University).

Gradidge, S., Zawisza, M., \& Harvey, A. (under review). The meat paradox: How people overcome cognitive dissonance within the context of animal use.

Hermanson, S. (2019). The problem is not discourses of production; it is production itself. Animal Sentience 25(29).

Kildal, C. L., \& Syse, K. L. (2017). Meat and masculinity in the Norwegian Armed Forces. Appetite, 112, 69-77. doi: 10.1016/j.appet.2016.12.032 
Kunst, J. R., \& Haugestad, C. A. P. (2017). The effects of dissociation on willingness to eat meat are moderated by exposure to unprocessed meat: A cross-cultural investigation. Appetite, 120, 356-366. doi: 10.1016/j.appet.2017.09.016

Kunst, J. R., \& Hohle, S. M. (2016). Meat eaters by dissociation: How we present, prepare and talk about meat increases willingness to eat meat by reducing empathy and disgust. Appetite, 105, 758-774. doi: 10.1016/j.appet.2016.07.009

Marino, L., \& Merskin, D. (2019). Intelligence, complexity, and individuality in sheep. Animal Sentience 25(1).

Palmer, C., \& Sandøe, P. (2019). Yes, sheep are smart but the moral question is still "Can they suffer?" Animal Sentience 25(24).

Piazza, J., \& Loughnan, S. (2016). When meat gets personal, animals' minds matter less: Motivated use of intelligence information in judgments of moral standing. Social Psychological and Personality Science, 7(8), 867-874. doi: 10.1177/1948550616660159

Rollin, B. (2019). Far more to sheep than meets the casual eye. Animal Sentience 25(7).

Rothgerber, H. (2012). Real men don't eat (vegetable) quiche: Masculinity and the justification of meat consumption. Psychology of Men \& Masculinity, 14(4), 363. doi: 10.1037/a0030379

Rothgerber, H. (2014). Efforts to overcome vegetarian-induced dissonance among meat eaters. Appetite, 79, 32-41. doi: 10.1016/j.appet.2014.04.003

Sevillano, V. (2019). Our ambivalent stereotypes of sheep. Animal Sentience 25(35).

Tian, Q., Hilton, D., \& Becker, M. (2016). Confronting the meat paradox in different cultural contexts: Reactions among Chinese and French participants. Appetite, 96, 187-194. doi: 10.1016/j.appet.2015.09.009

Woodford, P., \& Carter, A. (2019). Science, social critique, and the need for ethics. Animal Sentience 25(34). 